\title{
Percent Predicted Inspiratory Vital Capacity
}

National Cancer Institute

\section{Source}

National Cancer Institute. Percent Predicted Inspiratory Vital Capacity. NCI Thesaurus.

Code 124424

The maximum volume of gas an individual can inhale from the point of maximal

exhalation expressed as a percentage of the expected result value for healthy individuals of similar age, sex, height, and race. 